\title{
SENSITIVITY OF NON-CONTRAST COMPUTED TOMOGRAPHY FOR SMALL RENAL CALCULI WITH ENDOSCOPY AS THE GOLD STANDARD
}

\author{
Naeem Bhojani ${ }^{1}$, Jessica E. Paonessa ${ }^{2}$, Marawan M. El Tayeb ${ }^{3}$, James C. Williams, Jr., \\ Tariq A. Hameed ${ }^{5}$, James E. Lingeman ${ }^{6}$ \\ ${ }^{1}$ University of Montreal, Department of Urology, Montreal, Quebec, Canada \\ ${ }^{2}$ Syracuse University, Department of Urology, Syracuse, NY \\ ${ }^{3}$ Baylor Scott and White Health, Department of Urology, Temple, TX \\ ${ }^{4}$ Indiana University School of Medicine, Department of Anatomy and Cell Biology, Indianapolis, IN \\ ${ }^{5}$ Indiana University School of Medicine, Department of Radiology, Indianapolis, IN \\ ${ }^{6}$ Indiana University School of Medicine, Department of Urology, Indianapolis, IN
}

\section{Address all correspondence to:}

James E. Lingeman, M.D., FACS

Indiana University School of Medicine

1801 North Senate Blvd., Suite 220

Indianapolis, IN 46202

Tel: $317 / 962-2485$

Fax: 317/962-2893

Email: jlingeman@iuhealth.org

\section{Word Count:}

Abstract: 241

Text: 2127

Running head: CT versus URS for detection of renal calculi

Key Words: Computerized tomography, endoscopy, renal calculi

This is the author's manuscript of the article published in final edited form as:

Bhojani, N., Paonessa, J. E., El Tayeb, M. M., Williams Jr., J. C., Hameed, T. A., \& Lingeman, J. E. (n.d.). Sensitivity of NonContrast Computed Tomography for Small Renal Calculi with Endoscopy as the Gold Standard. Urology.

https://doi.org/10.1016/j.urology.2018.03.041 


\begin{abstract}
Objectives: To compare the sensitivity of non-contrast CT to endoscopy for detection of renal calculi. Imaging modalities for detection of nephrolithiasis have centered on abdominal x-ray (KUB), ultrasound (US), and non-contrast computed tomography (CT). Sensitivities of 58-62\% (KUB), 45\% (US), and 95-100\% (CT) have been previously reported. However, these results have never been correlated with endoscopic findings.
\end{abstract}

Methods: Idiopathic calcium oxalate stone formers with symptomatic calculi requiring ureteroscopy (URS) were studied. At the time of surgery, the number and location of all calculi within the kidney were recorded followed by basket retrieval. Each calculus was measured and sent for micro CT and infrared spectrophotometry. All CT scans were reviewed by the same genitourinary radiologist who was blinded to the endoscopic findings. The radiologist reported on the number, location, and size of each calculus.

Results: 18 renal units were studied in 11 patients. Average time from CT scan to URS was 28.6 days. The mean number of calculi identified per kidney was $9.2 \pm 6.1$ for endoscopy and $5.9 \pm 4.1$ for CT $(p<0.004)$. The mean size of total renal calculi (sum of longest stone diameters) per kidney was $22.4 \pm 17.1 \mathrm{~mm}$ and $18.2 \pm 13.2 \mathrm{~mm}$ for endoscopy and CT, respectively $(p=0.06)$.

Conclusions: CT scan underreports the number of renal calculi, probably missing some small stones and unable to distinguish those lying in close proximity to one another. However, the 
total stone burden seen by $\mathrm{CT}$ is, on average, accurate when compared to that found on endoscopic examination.

\section{Introduction}

Various imaging modalities have been employed for the detection of nephrolithiasis. Historically, intravenous urography was considered the gold standard for diagnosis of obstructing ureteral calculi. However, this technique has largely been replaced by unenhanced helical computed tomography (CT), which is considered the gold standard due to its high sensitivity (95-100\%), ability to identify secondary signs of stone passage and detection of additional pathology outside the urinary tract[1-5]. Today, some centers still use alternate imaging studies in the initial work-up of renal colic, including abdominal x-ray (KUB) and ultrasound (US) because they are readily available, inexpensive, and associated with little or no risk of radiation exposure. That being said KUB (58-62\%) and ultrasound (44.7\%) have low sensitivities for renal calculi. Furthermore, when interpreting the reported sensitivities of different radiographic tests, it should be mentioned that most published studies focus on identification of obstructing ureteral calculi as opposed to non-obstructing renal calculi[2-8]. Also, the sensitivities for detecting renal calculi with CT, KUB, and US have never been correlated with endoscopic findings.

Previous studies evaluating the sensitivity of CT with respect to the presence of ureteral calculi obtain confirmation of the diagnosis based on other imaging modalities, surgical removal, or stone passage[2-5, 8]. The principal objective of this study is to compare the sensitivity of non-contrast helical CT to flexible endoscopy for detection of renal calculi. Our hypothesis is 
that CT imaging will underestimate the total number of renal calculi. This study has important clinical implications for pre-surgical planning as well as increasing the importance of verifying all renal calyces at the time of ureteroscopy. To our knowledge, no study has been published that addresses this subject.

\section{Methods}

Our prospective study population included idiopathic calcium oxalate stone formers (ICSF) with symptomatic stones requiring ureteroscopy (URS). All patients consented to participate in our NIH supported stone pathogenesis project (NIH PO1DK56788) which was also approved by the Indiana University Institutional Review Board (\#1010002261). The selection criteria for patients involved in this study were the first 11 patients with multiple stones that could be removed ureteroscopically and known calcium oxalate stone formers. At the time of surgery, mapping of each collecting system was performed prior to treatment of any calculi. A ureteral access sheath was used in all cases. The collecting system was opacified with contrast and fluoroscopy was used to document the location of each calyx. Each calyx was endoscopically visualized and recorded using a digital flexible ureteroscope. The number and location of all calculi within the kidney were recorded. After mapping was completed, each calculus was removed using a stone retrieval basket. Individual calculi were labeled according to their location within the kidney, the longest diameter was measured in millimeters (mm) and analyzed for mineral content. In 8 of 18 renal units laser lithotripsy was necessary. In these cases, the stones were counted before laser lithotripsy was performed. In addition, all fragments were removed and reconstructed as best as possible by one of the authors (JCW). Once all the fragments were removed and reconstructed, they were measured as accurately as possible. 
Stone analysis included both micro CT and infrared spectrophotometry (Beck Analytical Services) for all cases. Patients were excluded if their stone analysis revealed mineral composition other than predominantly $(>50 \%)$ calcium oxalate $(\mathrm{CaOx})$. As such, in order to avoid potential biases, if stone analysis identified the presence of $>50 \% \mathrm{CaP}$, the patient was excluded from the study as such patients have been demonstrated to have a high rate of concomitant nephrocalcinosis. $^{9}$

All CT scans were reviewed by the same genitourinary radiologist (TH) who was blinded to the endoscopic findings. Using soft tissue as well as bone windows the radiologist reported on the number, location (upper, mid or lower pole), and size (in $\mathrm{mm}$; longest diameter) of each renal calculus. When the radiologist could not determine whether a calcification was within the renal collecting system, it was labeled as "unsure". However, "unsure" calcifications were included in the total number of calculi identified on CT. Only patients with recent $(<120$ days prior to surgery) CT scans were included. Patients who passed a stone or who underwent a stone removal procedure in the interval between obtaining their CT scan and surgery were also excluded.

Total number of calculi identified for each kidney pre-operatively by CT were compared with total numbers found on endoscopy using paired t-test. Similarly, the sum of the stone sizes (diameters, in $\mathrm{mm}$ ) determined pre-operatively by CT were compared with the sum of the stone sizes measured ex-vivo using paired t-test. All renal units were evaluated by CT and using endoscopy resulting in paired measurements. Using a paired student t-test with a significance level of $\alpha=0.05$, a sample of 18 renal units provides $85 \%$ power to detect an effect size of 0.75 between measurement methods in evaluating number of stones and total size of stones. Statistical 
calculations were done using JMP 10 (SAS Institute, Cary, NC) and significance was assumed with $p<0.05$.

\section{Results}

We studied a total of 18 renal units in 11 patients. Patient demographics are summarized in Table 1. The average time from CT scan to URS was 28.6 days, with a range of 0-119 days. The mean number of calculi identified per kidney was 9.2 \pm 6.1 (range: $2-24$ ) for endoscopy and

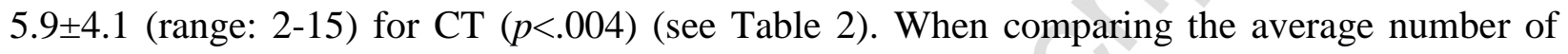
stones removed endoscopically compared to the average number of stones reported on CT, the mean difference was significantly greater when measured endoscopically $(3.3 \pm 4.2, p<0.004)$. More specifically, 13 of 18 renal units examined endoscopically, demonstrated more renal stones when compared to CT. In 3 renal units the number of stones were the same and in 2 renal units more stones were found on CT than endoscopically.

Total calculus size (mm) was measured as the sum of longest diameters for each calculus measured in $\mathrm{mm}$. The mean total size of calculi per kidney was $22.4 \pm 17 \mathrm{~mm}$ and $18.2 \pm 13.2 \mathrm{~mm}$ for endoscopy and CT, respectively (see Table 2. When comparing the total size of the stones per renal unit, the total size of calculi measured ex vivo and by CT did not differ (mean difference $=$ 4.2 $\pm 8.9 \mathrm{~mm}, p=0.06$ ). Finally, a total of 12 calcifications noted on CT were labeled "unsure" by the radiologist. These 12 calcifications were included in the total number of calculi counted for the CT scan so they did not inappropriately influence the results showing a greater number of calculi seen endoscopically. Additionally, revision of our endoscopic findings confirm that calcifications noted on CT and labeled as "unsure" by the radiologist were in fact actual small renal calculi. 
No statistically significant differences were found between time from CT scan to URS and difference in stones found and/or volume of stones found between radiologist reporting and endoscopy findings.

\section{Discussion}

Our findings show that, on average, more calculi were found in a kidney endoscopically than had been identified on CT. The design of the study--with CT scans obtained typically a few weeks before surgery--would give time for some small calculi to pass spontaneously, which would decrease the number of stone found endoscopically, but probably not enough time for new calculi to grow. Thus, it is remarkable that only 2 of the 18 renal units showed fewer calculi endoscopically than could be seen on CT.

Our previous research has identified three pathways by which renal calculi are retained within the kidney during their early growth including 1) the overgrowth of calculi on interstitial apatite plaque (also referred to as white plaque or Randall's plaque), 2) overgrowth onto mineral plugs extending from the ostia of inner medullary collecting ducts (IMCD), and 3) stones that grow completely within dilated IMCD in patients with medullary sponge kidney[9, 10].

ICSF, the subjects of the present study, form $\mathrm{CaOx}$ overgrowths on Randall's plaque within the renal papilla[11]. Randall's plaque forms in the basement membranes of the thin limbs of the loops of Henle, migrates to locations beneath the urothelium, and acts as the anchoring site for formation of these common $\mathrm{CaOx}$ calculi[10]. Calculus formation in these patients is not caused by systemic disease[12].

Our prior work has shown that all of the non-ICSF stone phenotypes can have mineral deposits in the form of ductal plugs or ductal stones[12]. Such frank nephrocalcinosis can 
complicate the interpretation of a CT scan[13]. Specifically, distinguishing a calcification noted on CT as a stone versus ductal plugging is problematic[14]. The same study was not able to show that Randall's plaque was visible by CT. Thus, we reason that in ICSF patients, calculi seen by CT are always in the urinary space. Therefore, our comparison between pre-operative CT identification of calculi and endoscopic findings would not be compromised by the presence of ductal plugs or stones, which would show up on CT, but which may not be as easily seen by ureteroscopy. For these reasons, patients who formed non-CaOx calculi or who formed calculi secondary to systemic disease were excluded from this study.

The visibility of stones on CT primarily depends on the calcium content. Technical factors affecting stone visibility also include slice thickness and overlap and also tube current and $\mathrm{KVp}[15]$. The most likely explanation for our findings include the limitation of slice thickness and similar density of calcium in adjacent stones, thereby limiting the separation of individual adjacent stones, when there is no clear intervening non-calcified tissue. Although, stone detection may be improved by reconstructing thinner sections, our study demonstrates limitation of current clinical imaging. Among the patients in this study, only one was imaged using a low-dose CT protocol with $3.0 \mathrm{~mm}$ cuts. The amount of radiation delivered using this technique is approximately 1 millisievert. The patient was very thin and the study was of high quality. The CT was obtained on the same day surgery was performed. Interestingly, in one of the kidneys, the number of calcifications identified on CT was higher than the number of calculi retrieved endoscopically. Whereas, the opposite was true of the contralateral kidney. An example of small $\mathrm{CaOx}$ stones overgrowing Randall's plaque that were not visualized on CT are shown in Figure 1. The findings also show that the size of the stone burden identified by CT correlated very well with the size measured upon stone removal. 
The most sensitive imaging modality currently available to detect renal calculi is the unenhanced helical CT. ${ }^{1-6}$ Other diagnostic tools such as US and KUB can also detect renal calculi but with less sensitivity[1, 6, 7]. Furthermore, upon revision of the endoscopic results by our GU radiologist, he has concluded that in several cases $(270 \mathrm{R}, 270 \mathrm{~L}, 285 \mathrm{R}, 285 \mathrm{~L})$ several stones were not visible on the CT. Additionally, it is possible that some stones could have been missed due to CT slice thickness and technique. Our findings are even more significant in the era of low dose and even ultra low dose CT protocols as this will likely decrease the sensitivity of renal calculi detection.

In summary, although the number of renal units examined in this study was small, this study suggest that endoscopy is more accurate than non-contrast CT for identifying calculi within the kidney. The clinical relevance of this finding is that it is plausible that patients presenting with a symptom complex and urinary parameters suggestive of renal calculi, in whom other sources for pain have been ruled out, may benefit from ureteroscopic evaluation of the renal collecting system. In a multi-center trial including our institution, removal of small nonobstructing calculi resulted in a durable pain relief response in $83 \%$ of patients[16]. Another recent study by Jura and colleagues reported their experience with 13 patients treated ureteroscopically for non-obstructing, calyceal calculi $\leq 4 \mathrm{~mm}$ in diameter. Either complete or partial resolution of pain was achieved in $85 \%$ and $15 \%$ of patients, respectively[17].

Furthermore, another clinical implication of our findings is that treatment/removal of small non-obstructing or subclinical calculi, identified at the time of treatment for a symptomatic calculus, may impact future stone episodes. When treating an obstructing ureteral calculus at our institution, we routinely perform flexible ureteroscopy and inspect the renal collecting system. 
Any incidentally discovered calculi within the kidney are removed. If tiny calculi attached to Randall's plaque are too small to be retrieved using a basket, they are brushed off the surface of the papillae and flushed into the renal pelvis where they are allowed to pass spontaneously. In theory, this could prevent subsequent growth of these tiny calculi into larger calculi, which may later become unattached and lead to symptomatic stone events in the future.

\section{Conclusion}

Unenhanced helical CT underestimates the number of renal calculi within a kidney, but does provide a good measure of total stone burden. Surgeons should be aware that the number of calculi in a kidney is likely to be higher than that indicated by CT.

Source of Funding: Supported by NIDDK P01 DK43881, P01 DK56788 


\section{References}

1. Ray, A.A., et al., Limitations to ultrasound in the detection and measurement of urinary tract calculi. Urology, 2010. 76(2): p. 295-300.

2. Smith, R.C., et al., Diagnosis of acute flank pain: value of unenhanced helical CT. AJR Am J Roentgenol, 1996. 166(1): p. 97-101.

3. Niall, O., et al., A comparison of noncontrast computerized tomography with excretory urography in the assessment of acute flank pain. J Urol, 1999. 161(2): p. 534-7.

4. Chen, M.Y. and R.J. Zagoria, Can noncontrast helical computed tomography replace intravenous urography for evaluation of patients with acute urinary tract colic? J Emerg Med, 1999. 17(2): p. 299-303.

5. Fielding, J.R., et al., Spiral computerized tomography in the evaluation of acute flank pain: a replacement for excretory urography. J Urol, 1997. 157(6): p. 2071-3.

6. Mutgi, A., J.W. Williams, and M. Nettleman, Renal colic. Utility of the plain abdominal roentgenogram. Arch Intern Med, 1991. 151(8): p. 1589-92.

7. Roth, C.S., B.A. Bowyer, and T.H. Berquist, Utility of the plain abdominal radiograph for diagnosing ureteral calculi. Ann Emerg Med, 1985. 14(4): p. 311-5.

8. Dalrymple, N.C., et al., The value of unenhanced helical computerized tomography in the management of acute flank pain. J Urol, 1998. 159(3): p. 735-40.

9. $\quad$ Coe, F.L., et al., Three pathways for human kidney stone formation. Urol Res, 2010. 38(3): p. 14760.

10. Williams, J.C., Jr., et al., Papillary Ductal Plugging Is a Mechanism for Early Stone Retention in Brushite Stone Disease. J Urol, 2018. 199(1): p. 186-92.

11. Evan, A.P., et al., Randall's plaque of patients with nephrolithiasis begins in basement membranes of thin loops of Henle. J Clin Invest, 2003. 111(5): p. 607-16.

12. Coe, F.L., et al., Plaque and deposits in nine human stone diseases. Urol Res, 2010. 38(4): p. 23947.

13. Bhojani, N., et al., Nephrocalcinosis in Calcium Stone Formers Who Do Not have Systemic Disease. J Urol, 2015. 194(5): p. 1308-12.

14. Krambeck, A.E., et al., Current computed tomography techniques can detect duct of Bellini plugging but not Randall's plaques. Urology, 2013. 82(2): p. 301-6.

15. Smith, R.C., J. Levine, and A.T. Rosenfeld, Helical CT of urinary tract stones. Epidemiology, origin, pathophysiology, diagnosis, and management. Radiol Clin North Am, 1999. 37(5): p. 911-52, v.

16. Gdor, Y., et al., Multi-institutional assessment of ureteroscopic laser papillotomy for chronic flank pain associated with papillary calcifications. J Urol, 2011. 185(1): p. 192-7.

17. Jura, Y.H., et al., Ureteroscopic treatment of patients with small, painful, non-obstructing renal stones: the small stone syndrome. Clin Nephrol, 2013. 79(1): p. 45-9. 


\section{Figure Legend}

Figure 1: An example of very small subclinical calcium oxalate stones overgrowing Randall's plaque.

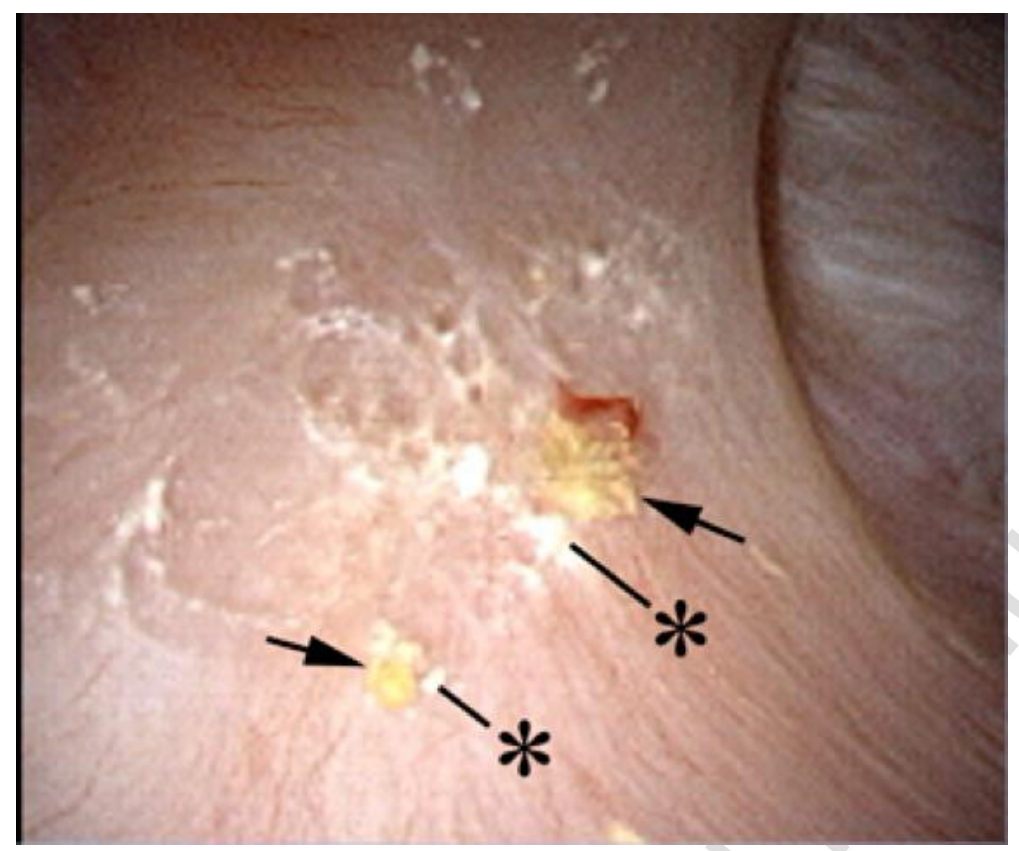

Arrow: stone

Star: Randall's plaque 


\section{Table 1: Patient demographics}

\begin{tabular}{|c|c|}
\hline Age (years) & $21-74($ mean $=48)$ \\
\hline Male & $7(63.6 \%)$ \\
\hline Female & $4(36.4 \%)$ \\
\hline Unilateral URS & 3 \\
Right & 1 \\
Left & 2 \\
\hline Bilateral URS & 8 \\
\hline Stone Analysis & $11 \mathrm{CaOx}(100 \%)$ \\
\hline
\end{tabular}

URS: Ureteroscopy

CaOx: Calcium oxalate 
Table 2: Number and size of calculi per kidney (CT versus endoscopy)

\begin{tabular}{|c|c|c|c|c|c|c|c|}
\hline & $\begin{array}{c}\text { TOTAL } \\
\text { NUMBER }\end{array}$ & $\begin{array}{c}\text { TOTAL } \\
\text { NUMBER }\end{array}$ & $\begin{array}{c}\text { DIFFER } \\
\text { ENCE } \\
\text { IN } \\
\text { TOTAL } \\
\text { NUMBE } \\
\text { R OF } \\
\text { STONE } \\
\text { S }\end{array}$ & $\begin{array}{c}\text { TOTAL } \\
\text { SIZE (MM) }\end{array}$ & $\begin{array}{c}\text { TOTAL } \\
\text { SIZE (MM) }\end{array}$ & \begin{tabular}{|c} 
DIFFER \\
ENCE \\
IN \\
TOTAL \\
SIZE OF \\
STONE \\
S
\end{tabular} & $\begin{array}{c}\text { DEL } \\
\text { AY } \\
\text { FRO } \\
\text { M } \\
\text { SCA } \\
\text { N } \\
\text { TO } \\
\text { URS } \\
\text { (d) }\end{array}$ \\
\hline $\begin{array}{c}\text { KR } \\
\mathbf{P}\end{array}$ & $\begin{array}{c}\text { ENDOSC } \\
\text { OPY }\end{array}$ & CT & & $\begin{array}{c}\text { ENDOSCO } \\
\text { PY }\end{array}$ & CT & & \\
\hline $\begin{array}{c}265 \\
L\end{array}$ & 24 & 14 & +10 & 57.5 & 47 & +10.5 & 119 \\
\hline $\begin{array}{c}269 \\
L\end{array}$ & 19 & 15 & +4 & 68 & 52.8 & +15.2 & 0 \\
\hline $\begin{array}{c}270 \\
\mathrm{R}\end{array}$ & 12 & 2 & +10 & 26.5 & 5.1 & +21.4 & 29 \\
\hline $\begin{array}{c}270 \\
L\end{array}$ & 12 & 5 & +7 & 26 & 14 & +12 & 29 \\
\hline $\begin{array}{c}284 \\
\mathrm{R}\end{array}$ & 7 & 12 & -5 & 16 & 23.6 & -7.6 & 53 \\
\hline $\begin{array}{c}285 \\
\mathrm{R}\end{array}$ & 11 & 7 & +4 & 35.5 & 23.1 & +12.4 & 62 \\
\hline $\begin{array}{c}285 \\
L\end{array}$ & 12 & 3 & +9 & 23 & 9.4 & +13.6 & 62 \\
\hline $\begin{array}{c}294 \\
\mathrm{R}\end{array}$ & 15 & 7 & +8 & 23.5 & 17.4 & +6.1 & 1 \\
\hline $\begin{array}{c}294 \\
\mathrm{~L}\end{array}$ & 7 & 6 & +1 & 10.9 & 16.7 & -5.8 & 1 \\
\hline $\begin{array}{c}295 \\
\mathrm{R}\end{array}$ & 3 & 3 & 0 & 8.4 & 7.3 & +1.1 & 97 \\
\hline
\end{tabular}




\begin{tabular}{|c|c|c|c|c|c|c|c|}
\hline $\begin{array}{c}301 \\
\mathrm{R}\end{array}$ & 6 & 3 & +3 & 10.9 & 9.5 & +1.4 & 2 \\
\hline $\begin{array}{c}301 \\
\text { L }\end{array}$ & 3 & 3 & 0 & 11 & 9 & +2 & 2 \\
\hline $\begin{array}{c}315 \\
\mathrm{R}\end{array}$ & 2 & 2 & 0 & 28 & 20 & +8 & 0 \\
\hline $\begin{array}{c}315 \\
L\end{array}$ & 13 & 9 & +4 & 19.3 & 28 & -8.7 & 0 \\
\hline $\begin{array}{c}325 \\
\mathrm{R}\end{array}$ & 3 & 2 & +1 & 8.0 & & 0 & 29 \\
\hline $\begin{array}{c}325 \\
L\end{array}$ & 5 & 5 & 0 & 8.3 & 15.5 & -7.2 & 29 \\
\hline $\begin{array}{c}329 \\
\mathrm{R}\end{array}$ & 3 & 4 & -1 & 3.9 & 7.8 & -3.9 & 0 \\
\hline $\begin{array}{c}329 \\
L\end{array}$ & 9 & 4 & +5 & 18.5 & 13.5 & +5 & 0 \\
\hline $\begin{array}{l}\text { ME } \\
\text { AN }\end{array}$ & 9.2 & 5.9 & +3.3 & 22.4 & 18.2 & +4.2 & 28.6 \\
\hline Tot & sure & & & & & & \\
\hline
\end{tabular}

